\title{
Design and Implementation of Smart Dust Sensing System for Baghdad City
}

\author{
Hussien A. Mohammed \\ University of Information Technology and Communication \\ dr.hussien.a.mohammed@uoitc.edu.iq
}

Recived : 22\11\2017

Revised : 18\12\2017

Accepted : 21\12\2017

Available online : $26 / 1 / 2018$

DOI: 10.29304/jqcm.2018.10.1.353

\begin{abstract}
The atmosphere in the world and especially in Iraq is yearly exposed to many dust storms that cause dust floated, which negatively affects the health of people, animals and agriculture. In this research, a system is proposed that used sensor to continuously measure the level of dust in the air of Baghdad city 24 hours $/ 7$ days a week. Then analyzing these measurements to determine the level of risk impact on people health especially people with respiratory diseases. The proposed system has the ability of sending warning text message expressing the level of potential threat to the people.

In order to accelerate the rapid processing, an accurate Arduino Uno microcontroller was used to measure the density of the dust and make the required processing. In addition to, using the Global System for Mobile Communications (GSM) type SIMS900 as SMS sender.

The advantages of this system is represented by its ability to alert the people about air pollution in real time, ease of use (where mobile devices are available to most people in Baghdad) and the low cost of sending a message.
\end{abstract}

Keywords: Dust Sensor, Dust Storms, GSM, Mobile Communications, SMS.

\section{Introduction}

Often sand and dust storms (SDS) influence some countries because their geographical position. These dust storms hit many countries and unfortunately, it hit Iraq and last for days. In summer season, the climate in Iraq is dry, hot and dusty. A northwest wind drive dust storms and this wind known in Arabic language by "Shimali" (means wind come from the north). At any time of the year, may rip via the River valleys of Tigris and Euphrates in central and southern of Iraq and storm almost continuously through June and July as shown in figure 1. Sometimes, "Shimali" might blow in the months of August and September. These winds can continue for more than one day, strength during the day, weak at night, and sometimes create ruined dust storms [1].

In addition to, the Iraqi Ministry of Environment recorded 122 dust storms and 283 dusty days. The forecasts predict 300 dusty days and dust storms yearly may occur in the next ten years [2].

Living in environment with such condition causes lung illnesses including asthma and constrictive bronchiolitis [3]

Further, 300 million people in the whole world suffer from asthma as estimated by the American Academy of Allergy Asthma and Immunology. 


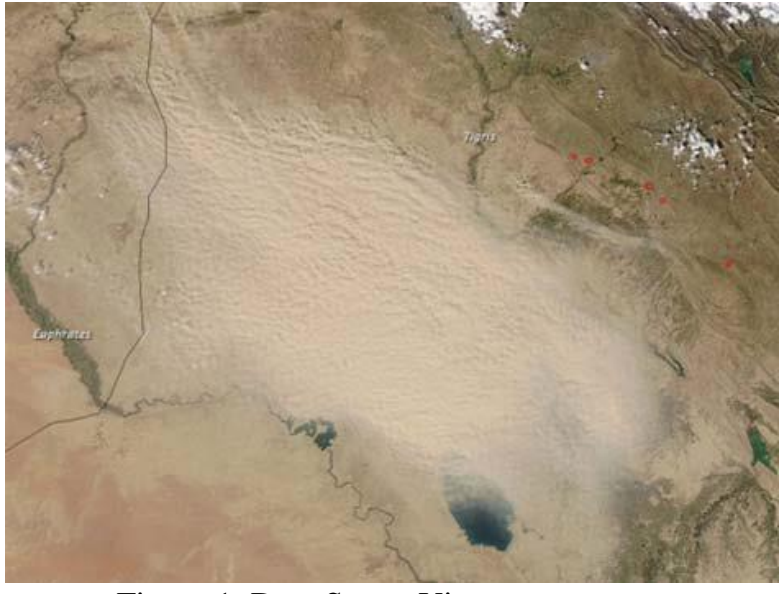

Figure 1. Dust Storm View

Asthma is regarded as burden in high-income countries because it cost the government too much. While, the most deaths which caused by asthma occur in countries of low and middle-income. However, there is not reliable epidemiological investigation and studies to define the number of people who suffer from asthma in many developing countries. Moreover, it is hard to diagnose and tackle the asthma disease in developing countries.
This is attributed to the limited available data and high expense that required to overcoming this disease. In general, a physician requires around six months for each individual to be diagnosed by asthma [4].

A study started in September 2013 and lasted to March 2014. This study targeted people aged 4-15 years who attending school. All individuals aged 415 years in the selected group were invited to participate in the study. The student's schools were randomly selected from two cities in Iraq Baghdad and Rumadi. This study investigates the spread of asthma symptoms in children that include: ever wheezed, current wheezing, speech limitation, ever diagnosed with asthma, dry cough and exerciseinduced asthma. The results were as presented in table 1 [5].

Table 1. The Asthma Symptoms Prevalence in Children at Iraqi Schools

\begin{tabular}{|c|c|c|c|}
\hline Asthma Symptoms & Boys ( No.=307) & Girls (No. =486) & Total (No. = 793) \\
\hline ever wheezed & $21.2 \%$ & $17.7 \%$ & $19.0 \%$ \\
\hline $\begin{array}{c}\text { current wheezing } \\
\text { speech limitation }\end{array}$ & 16.3 & $13.2 \%$ & $14.4 \%$ \\
\hline ever diagnosed with asthma & $19.9 \%$ & $1.9 \%$ & $2.3 \%$ \\
\hline dry cough & $19.2 \%$ & 16.9 & $18.0 \%$ \\
\hline exercise-induced asthma & $16.3 \%$ & 11.1 & $14.2 \%$ \\
\hline
\end{tabular}

Furthermore, the U.S. Environmental Protection Agency presented a guide of Air Quality Index (AQI) impacts on human health.
Table 2 describes the effects of increasing AQI on human health. 
Table 2. The effects of Air Quality Index on Human Health

\begin{tabular}{|c|c|c|}
\hline Value of AQI & Health Level & Actions to Protect Your Health \\
\hline$(0-50)$ & Good & None \\
\hline$(51-100 *)$ & Moderate & $\begin{array}{l}\text { Unusually sensitive people should consider } \\
\text { reducing prolonged or heavy outdoor } \\
\text { exertion. }\end{array}$ \\
\hline$(101-150)$ & $\begin{array}{l}\text { Unhealthy for } \\
\text { Sensitive Groups }\end{array}$ & $\begin{array}{l}\text { The following groups should reduce } \\
\text { prolonged or heavy outdoor exertion: } \\
\text { - People with lung disease, such as asthma } \\
\text { - Children and older adults } \\
\text { - People who are active outdoors }\end{array}$ \\
\hline$(151-200)$ & Unhealthy & $\begin{array}{l}\text { The following groups should avoid prolonged } \\
\text { or heavy outdoor exertion: } \\
\text { - People with lung disease, such as asthma } \\
\text { - Children and older adults } \\
\text { - People who are active outdoors } \\
\text { Everyone else should limit prolonged outdoor } \\
\text { exertion }\end{array}$ \\
\hline$(201-300)$ & Very Unhealthy & $\begin{array}{l}\text { The following groups should avoid all } \\
\text { outdoor exertion: } \\
\text { - People with lung disease, such as asthma } \\
\text { - Children and older adults } \\
\text { - People who are active outdoors } \\
\text { Everyone else should limit outdoor exertion. }\end{array}$ \\
\hline$(301-500)$ & Hazardous & $\begin{array}{l}\text { Everyone should avoid all physical activies } \\
\text { outdoors }\end{array}$ \\
\hline
\end{tabular}

Usually, when AQI values are less 100, the air quality is regarded well. As value of AQI is increasing, the effects are getting more risk to human health [7].

Moreover, the recent advances in cellular networks has opened up new era of devices that use wireless networks for particularistic intents. The term Machine 2 Machine (M2M) means two communicated machines and it used for Machine to Mobile too, in addition to other concepts. The combination of $\mathrm{M} 2 \mathrm{M}$ and internet of things presented new revolution of technology that would be producing various business in future. It will resulting in increase the number types of applications. M2M technology offers the ability of sending the world physical information between two machines through the communication networks and other platforms.

As a result, a monitoring system that able to sense the environmental condition outdoors for allergic people (or people with asthma) is required. Especially with the recent developing in computer technology, sensors and information systems [6] that facilities introducing such controlling system.

The rest of this paper are structured as follows: Section 2 explained the related work. Proposed system presents in section 3. Section 4 details analyzing results. Dust sensor is described in section 5. Proposal Implementation explained in section 6. Conclusion is described in section 5 .

\section{Related work}

The authors in [8] studied the storms of sand and dust in Iraq and the near areas. They classified the major factors that caused the sand and dust storms development. In addition to, presenting these storms effects on the economic losses and human's health.

In [9] the authors used micro electro-mechanical sensors and wireless network sensor to design and implement a smart dust sensor.

The authors in [10] measured the temperature, humidity, atmospheric pressure and dust density by developing a new technique for weather station. A web server is developed in order to process the recorded data which are collected by sensors. Finally, the new system has the ability of alerting user by web page or by text messages.

The research in [11] presented new technique that sense the dust intensity in air. This proposal based on Radio Frequency Identification technology (RFID) to transmit sensed data via wireless network. RFID technology includes wireless sensors so it get the benefits of small and cheap RFID tags to the wireless sensor networks. 


\section{Proposed system}

The proposed system consists of three components: dust sensor (operation and evaluated), processing, and the process result is send to Allergic People via network (GSM). Figure 2 shows the block diagram of proposed system. It is consists of microcontroller, dust sensor, GSM that communicates to Mobile phone, and power supply.

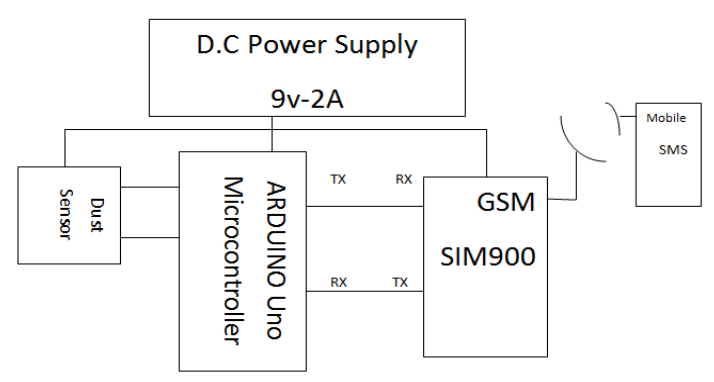

Figure 2. The Block Diagram of the Proposed System.
The dust sensor sense the outdoor environment periodically (means every 5 minutes or based on required setting). Then, send sensed data to controller which analyses them and send alert message to user mobile. The content of message is vary based on the received data (Excellent weather, Good weather, Unhealthy weather, Dangerous weather, or Emergency weather). Figure 3 shows the proposed system architecture. The dust sensor measures the dust regularly (for example every 1 minute) then specify the measured value on human health based on table 2. Hence take the action upon the specified value of dust.

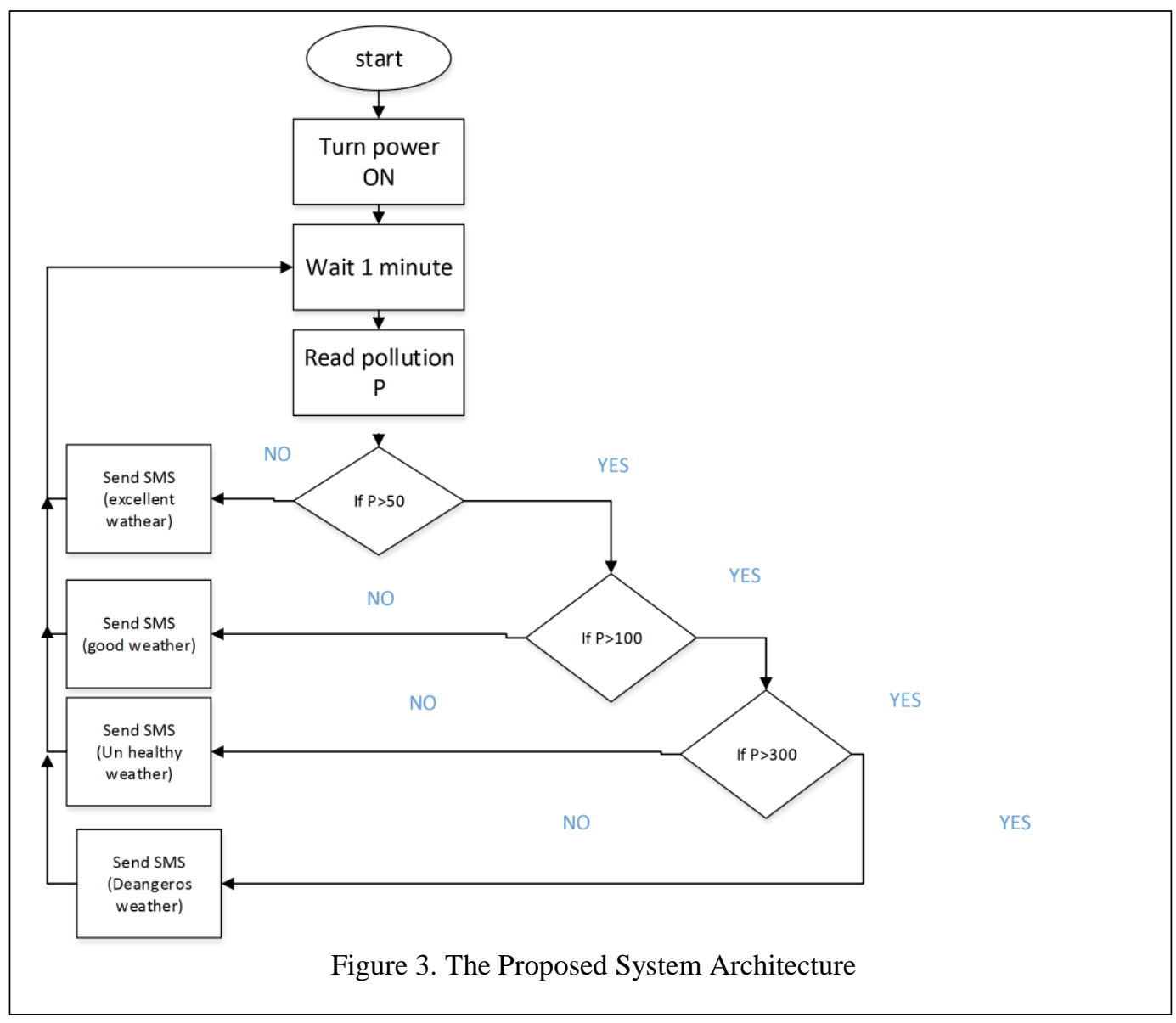




\section{Dust sensor}

Infrared electromagnetic wave (IR) is used for counting the density of dust particle. The transmitted beam of IR groves may be contain this particle where the scattered light is detected by using photodiode. Optical lens is used to focusing and collecting beam upon detector as show on figure (4).

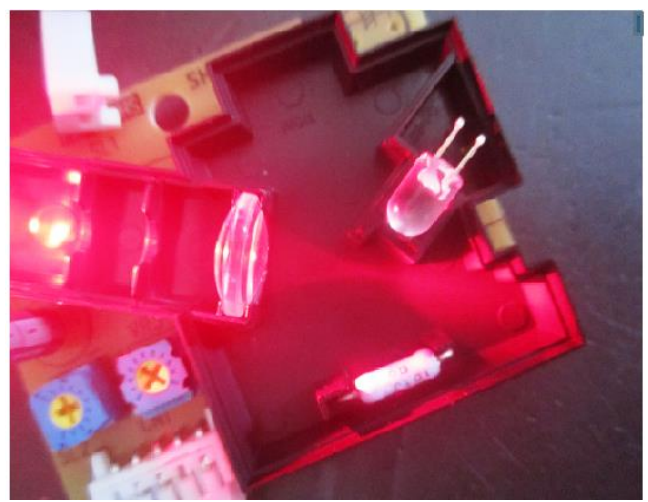

Figure 4. The Construction of Dust Sensor

The used heat generator is represented by Resistor of $100 \Omega$, which is allowed to circulate in to sensor groves. The IR photo diode is transmit train of pulses as a plus width modulator (PWM). The sensor detects particle of a diameter $(1-10 \mu \mathrm{m})$, where the detectable range of particle is depending on the detectable range setting of dust concentration $0-1.4 \mathrm{mg} / \mathrm{m}^{3}$ and the raise time of this sensor is about 1 mint after power on. The suitable supply voltage is 5 volt direct current. The output signal without dust is shown in figure (5).

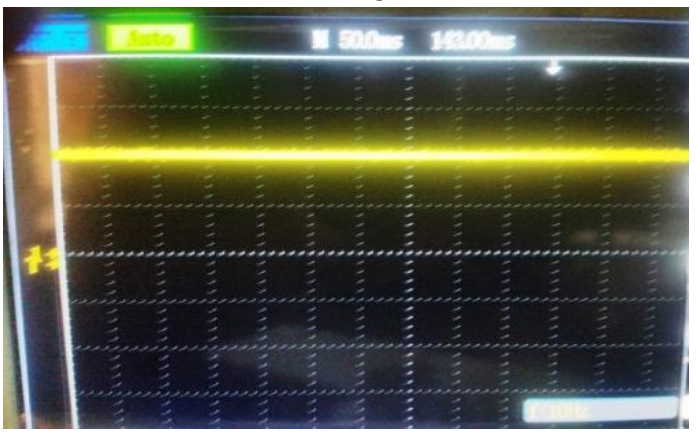

Figure 5.The Output of Dust Sensor without Dust

Dust will be detected when it scattered the IR light as shown in figure (6). The pulse width of the output is proportional to the dust density.

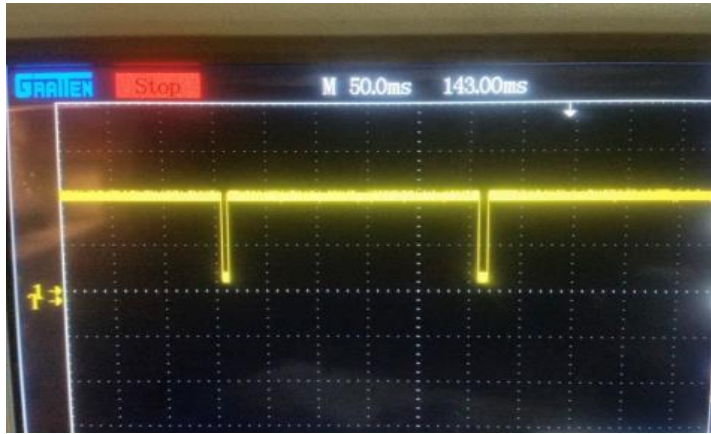

Figure 6.The Pulse Width with Dust

\section{A. Sensor output}

The output of the sensor is fluctuated between low and high stat when dust particles enter the groves of sensor. Otherwise the output of the sensor is not fluctuated.

Low plus (LO) proportional with dust construction, when measured what they call LO pulse occupancy (LPO), the constriction of dust can be determined for 30 second time period can be used to measure LOP as show in figure (7).

Low ratio $[\%]=\mathrm{t}(\mathrm{sec}) / 30(\mathrm{sec}) * 100$

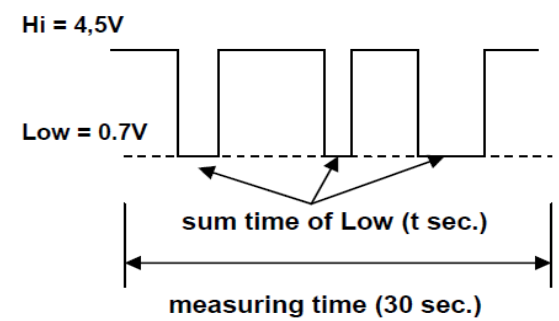

Figure (7) Low Ratio

Low ratio represent the value of dust particle that can be measured, as a number of particle and its diameter are show in figure (8)

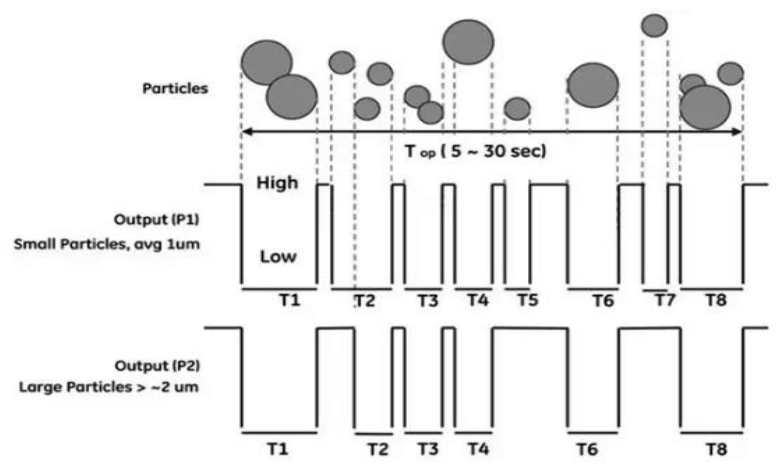

Figure (8) low ratio measurement with assumed two different particle diameter 


\section{B. Dust density measurement and process}

In order to measure the density of the dust under test, electronics microcontroller is used of type (Arduino Uno). The output of dust sensor is connected to it as shown in figure (9).

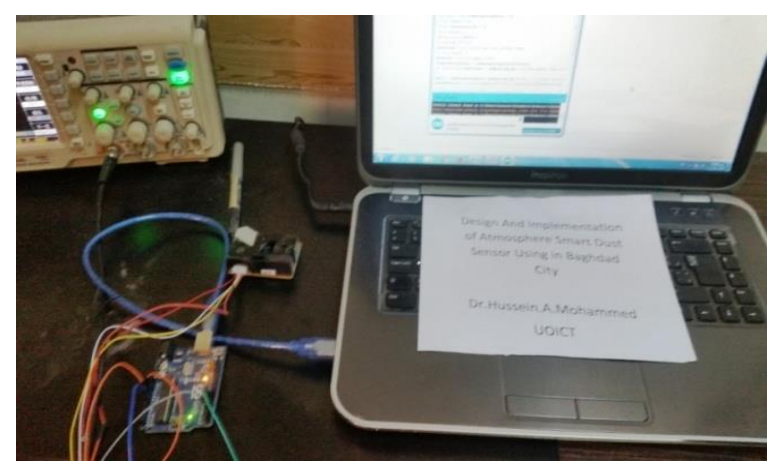

Figure 9. The Connection of Dust Sensor with Arduino Microcontroller Board

The Arduino deriver software has been downloaded and installed on personal computer to communicate with microcontroller bored by connecting it using (USB port). The output of this software appear on a monitor named (serial monitor). Figure 10 shows serial monitor when it is presenting the output of dust sensor in case of concentration $=0.62 \mathrm{pcs} / 0.01 \mathrm{cf}$. When increase the construction of a dust density the serial monitor of Arduino microcontroller

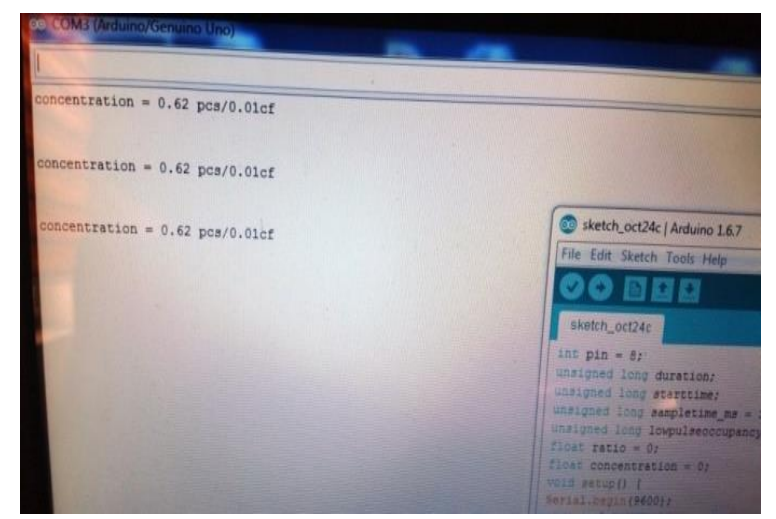

Figure 10.The Serial Monitor Presenting the Output 0.62 pcs/0.01cf of Dust Sensor

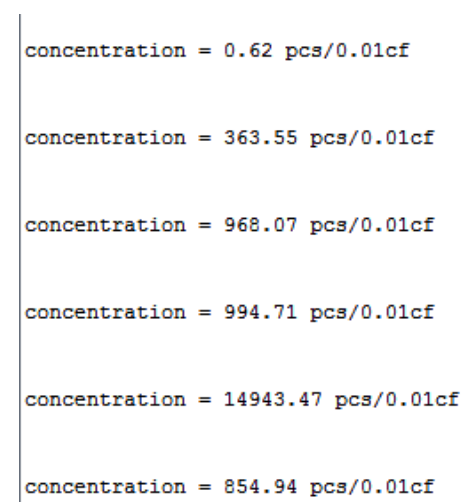

Figure 11.The Serial Monitor Presenting the Output

\section{Proposal Implementation}

The Arduino platform has been chosen to implement the proposal system because it's open source prototype platform. Arduino programming language is used to programmer the microcontroller on the board where this language is based on Wiring and the Arduino environment Processing. The Arduino Uno is a microcontroller that based on the ATmega328.

There are many advantages when using this type of microcontroller in term of low power CMOS, 8-bit based on the (AVR) that enhance the reduced instruction set computer RISC architecture which provide a small, highly-optimized set of instructions which is produce a power full instructions in a single clock per cycle. In addition to, the throughputs of this category is about million instructions per second (MIPS). Therefore the power consumption automatic versus processing speed.

The features of microcontroller are $32 \mathrm{~K}$ bytes Programmable Flash, Read-While-Write capabilities, 1K bytes EEPROM, 2K bytes SRAM, three flexible Timer, internal and external interrupts

The implementation of microcontroller includes two steps, which are described as follows:

\section{A. Software Design}

Software design consist of two parts: programming Arduino Uon and then Reading the measurements of sensor in order to forward the gathering data when requested. 
Microcontroller is programmed to send status of a sensor i.e. number of readings, time interval and to be used to get sensor readings. In addition to using the microcontroller as a storage to save data in it and retransmit (in GSM network) when it required. Therefore it increase its reliability.

\section{B. Hardware Connection}

The microcontroller is connect to GSM board by using Arduino board to enable it from sending and receiving SMS with ratio of dust based on collected and processed data.

SIM900 board is implemented to send SMS as shown in figure (11). The SIM900 shield has a modem and transfers processed data to the GSM network by connect the modem to subscriber identification module (SIM) card that placed in GSM board (low level communication). Then connect to the mobile company (Zain). The last connects to Mobile company Servers which will send a SMS to patient.

The resulted message can be sent to the asthma patients with dust level by using the Arduino program. The modem need $12 \mathrm{v}, 1 \mathrm{~A}$, in order to operate reliable. The baud rate of GSM board is set is to 19200 symbols per second, the transmitter of Arduino Uon pin TX is connected to the GSM receiver pin RX. While the receiver of Arduino Uon pin RX is connected to transmitter pin TX of GSM

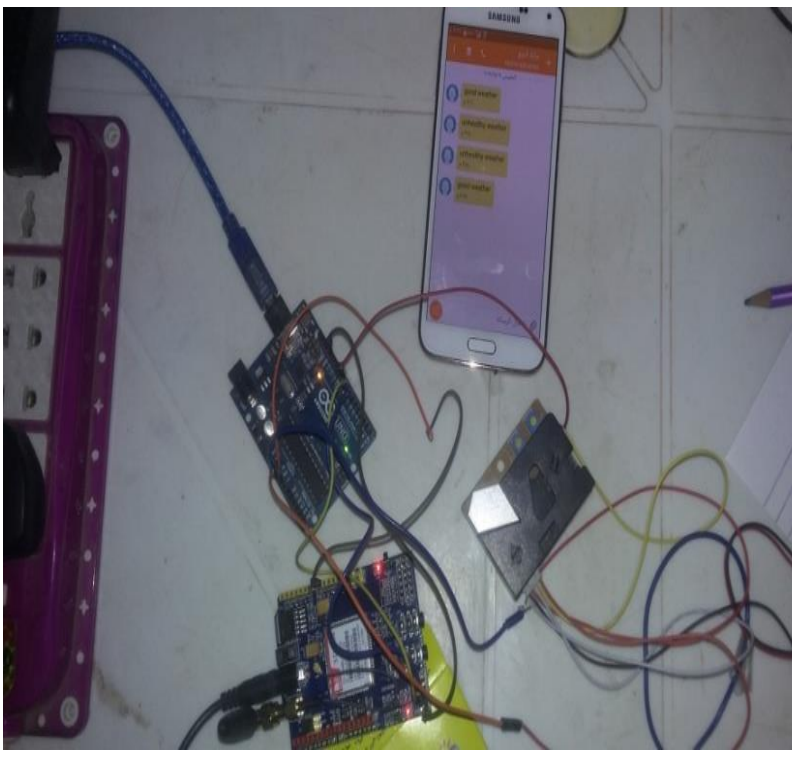

Figure 12. The implemented SIM900 Board

\section{Conclusion}

In this paper, a portable system has been designed and implemented that can monitor the level of air dust in real time 24 hours / 7 days in Baghdad city. The proposed system deploy dust sensor to sense the dust level in air, process and transmit the information to a mobile devices through the mobile company. This new approach provide real time, accurate and automated machine to mobile communication that means the sensors can send data to Phone devices via GSM technology. The dust sensor can be placed anywhere and the data of dust density can be gathered and sent SMS text message upon the read data. The proposed system can be used to monitor quality of the air in many aspects. It can be used in street, home, hospital and many other places for daily monitoring. The system will contribute to reduce the risk of health condition for many patients and in some cases save their lives. In addition to, the proposed system will reduce the patient stay at hospital if s/he need to, since they will be ready to take all the required procedures when receiving and reading the sms. The sms may include instructions for them on how to act when dust storms occur.

\section{References}

[1] Varoujan K. Sissakian, Nadhir Al-Ansari, and Sven Knutsson, "Sand and dust storm events in Iraq", Natural Science, Vol.5, No.10, 10841094

(2013)

http://dx.doi.org/10.4236/ns.2013.510133.

[2] Kobler, M. (2013) Dust storms of Iraq, UN Secretary General for Iraq, A ministerial meeting in Nairobi, Kenya. http://www.term123.com/dust-storms-ofiraq/\#mh32BcOB4S6cRkIG.99

[3] Harrington, A. D., M. P. Schmidt, A. M. Szema, K. Galdanes, S. E. Tsirka, T. Gordon, and M. A. A. Schoonen (2017), The role of Iraqi dust in inducing lung injury in United States soldiers-An interdisciplinary study, GeoHealth, 1, 237-246, doi:10.1002/2017GH000071.

[4] Maris Brummel, "Asthma in Developing Countries", the Borgen Project, 4 MAR 2014. https://borgenproject.org/about-us/

[5] Dr Aya Rahman Lafta and Dr Mohammed Shamssain, "Comparison of the Prevalence Rates of Asthma and Allergies Between UAE and Iraqi Schoolchildren", EUROPEAN JOURNAL OF PHARMACEUTICAL AND MEDICAL RESEARCH, ejpmr, 2016,3(3), 1522 
[6] Ron Williams and Vasu Kilaru "Air Sensor Guidebook" National Exposure Research Laboratory U.S. Environental Protection Agency, 2014

[7] U.S. Environmental Protection Agency Office of Air Quality Planning and Standards Outreach and Information Division Research Triangle Park, NC, "A Guide to Air Quality and Your Health ", February 2014 EPA-456/F14-002

[8] Varoujan K. Sissakian1, Nadhir Al-Ansari, Sven Knutsson, "Sand and dust storm events in Iraq", V. K. Sissakian et al. / Natural Science 5 (2013) 1084-1094.

[9] Roopal Gautam1, Sandhya Kumari2, Shuchi Chaudhar, "SMART DUST: AN EMERGING TECHNOLOGY”, International Journal Of Advance Research In Science And Engineering, IJARSE, Vol. No.2, Issue No.10, October 2013
[10] S. H. Parvez, J. K. Saha, M.J. Hossain, H. Hussain, Md. M. A. Ghuri, T. A.Chowdhury, Md. M. Rahman, N.Z. Shuchi8, A. Islam, M. Hasan And B. Paul, "A Novel Design and Implementation of Electronic Weather Station and Weather Data Transmission System Using GSM Network", WSEAS Transactions on Circuits and System, https://www.scribd.com/document/334915 699/a085801-435.

[11] Shyam D. Bawankar, Sonal B. Bhople \& Vishal D. Jaiswal, "Mobile Networking For "Smart Dust" With RFID Sensor Networks", International Journal of Smart Sensors and Ad Hoc Networks (IJSSAN), ISSN No. 2248-9738 (Print), Vol-2, Iss-3,4, 2012.

\section{تصميم وتثقيذ نظام تحسس غبار ذكي لمدينة بغداد$$
\text { جامعة تكنولوجين عبد الرضوات محمد والاتصالات }
$$ dr.hussien.a.mohammed@uoitc.edu.iq}

\footnotetext{
| (المستخلص :

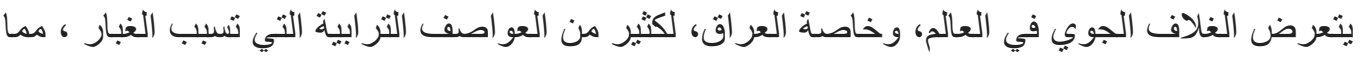

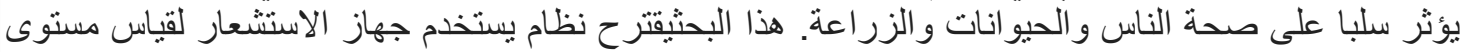

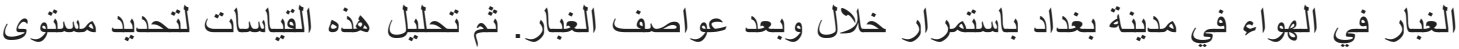

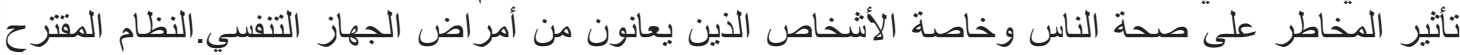

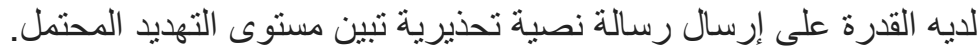

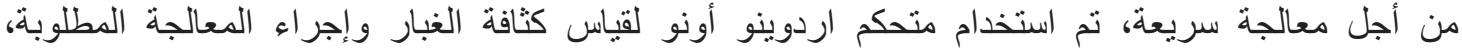

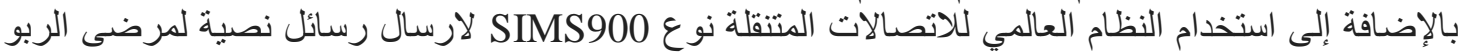

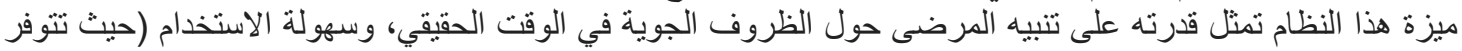

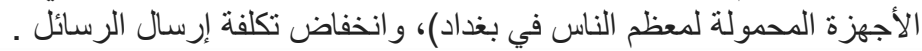

